\title{
Experimental study of the local scouring around sloped piers and its estimation using statistical tools
}

\author{
NAZILA KARDAN ${ }^{1, *}$, MEHDI REZAIE ${ }^{2}$ and MEHDI DINI ${ }^{1}$ \\ ${ }^{1}$ Department of Civil Engineering, Azarbaijan Shahid Madani University, Tabriz, Iran \\ ${ }^{2}$ Department of Civil Engineering, University of Maragheh, Maragheh, Iran \\ e-mail: n.kardan@azaruniv.ac.ir
}

MS received 24 October 2018; revised 12 June 2019; accepted 2 July 2019

\begin{abstract}
Local scouring around sloped bridge piers in steady currents was studied both experimentally and mathematically. The effects of different inclination angles, flow intensities, flow depths, and pier size on local scouring were investigated. The experimental results show that the scouring depth increases with an increase in the values of discharge and pier width. The scouring depth for the sloped piers is smaller than the vertical piers one and the maximum scouring depth continuously decreases as the pier inclination angle increases. Prediction of the scouring depth around bridge piers using analytical models can be utilized in the feasibility studies of different models, and evaluations of the parametric analytical. Therefore, it was tried to model the scouring depth as a function of Froude number, flow intensity, and relative roughness parameters using non-dimensional analysis. The regression analysis based models were introduced to determine the scouring depth at upstream side of the pier using experimental tests data. Step-wise linear regression showed that the value of relative scouring depth has considerably good correlation only with two non-dimensionless parameters of inclination angle and normalized approaching flow depth. In this regard, some linear and nonlinear regression tools were utilized to establish functional relationships between these variables. Statistical indices and residual analyses of the models revealed the suitability of the models. Comparison of the experimental and predicted value of relative scouring depth illustrates that the suggested models can reasonably predict this parameter.
\end{abstract}

Keywords. Scouring; bridge pier; sloped pier; statistical tools; regression analysis.

\section{Introduction}

Hydraulic structures constructed at alluvial beds may be damaged during floods and the scouring of the river bed is known as the main cause of damage [1-3]. Scouring is a natural phenomenon caused by an interaction of the water flow and sediment particles and occurs when the critical condition for initiation of sediments transport exceeded locally [4]. Scouring in the bed of bridge piers is the main cause of bridge failure in the worldwide [5-9]. Many investigations have been conducted to study the local scouring phenomenon using vertical bridge piers and the effect of countermeasures methods to decrease the local scouring [10].

A few experimental and/or numerical studies are available on the effect of piers inclination on the local scouring. It has been already known that the slope of the upstream and downstream face of the pier, relative to the vertical plane, is one of the most important parameters affecting scouring. Breusers and Raudkivi [11] showed that in the piers widened upward, the scouring depth increases and in

*For correspondence

Published online: 03 October 2019 the narrow piers in upstream the scouring depth decreases. Sumer et al [12] investigated the conical piers with different side slopes and measured the bed shear stresses around them. Fredsoe and Sumer [13] reported remarkably reducing the non-dimensional scouring depth around two conical piers with large side angle of $45^{\circ}$ and $60^{\circ}$. The side slope increases in conical piers lead to increasing the pier diameter at the bed level which causes to decrease the relative scouring depth, but intensify the absolute scouring depth. The large side slopes in the conical or semi-conical piers cause these models become inapplicable as bridge piers in the rivers because they have limited width. In addition, a large value of blockage ratio was seen in conical models. Considering these problems, used the inclined piers instead of the conical ones, firstly proposed by Bozkus and Yildiz [14]. They investigated a downstream inclined single pier with circular cross-section and reported that increasing the inclination angle of the pier towards downstream result in a significant decrease in local scouring depth (figure 1).

Cesme [15] conducted a series of new experiments with considering the inclination angle as an important parameter. The presented models are more practical and feasible 


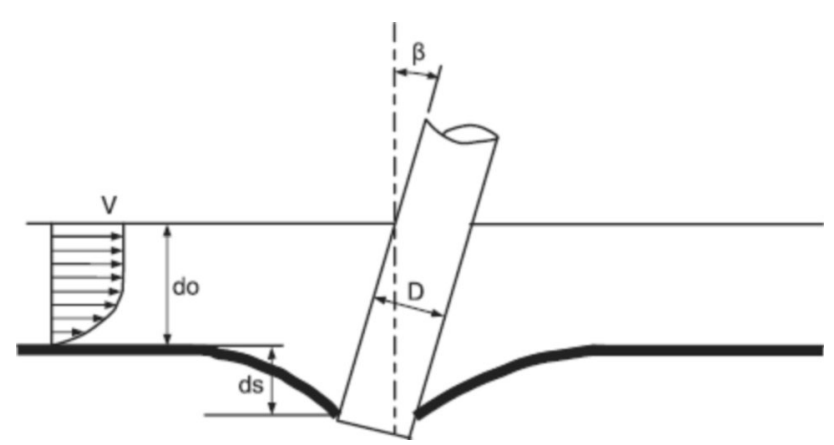

Figure 1. Introduced model by Bozkus and Yildiz [14].

since they have dual piers that inclined in both upstream and downstream directions (figure 2). Özlap [16] experimentally studied the inclination effect of the most upstream and downstream piers on the local scouring around the inclined group piers with 3 inclination angles of $5^{\circ}, 10^{\circ}$, and $15^{\circ}$ under clear-water condition. The results revealed that applying inclination in the group piers reduces substantially the scour depth; especially, scouring reduction around the upstream pier is notable. However, the interaction of the wake vortexes between the piers is the most important parameter that has not been considered in investigation of the inclined piers. In addition, the maximum slope that can be applied in these models is limited by the pier height.

Regarding these problems about inclined piers, it can be concluded that the inclined piers have very advantageous over the vertical piers, but fundamental changes should be applied to overcome their hydraulically and structural problems and make them more applicable. Therefore, in this research, a new series of sloped models having roundnosed rectangular cross-section investigated and a large values of inclination angle considered without any structural limitation in their designing. In addition, in comparison to the conical and inclined piers, it is expected that considerable advantages would be achieved in terms of both shortened construction period and reduced blockage ratio. Figure 3 shows the proposed model piers that experimentally and numerically investigated.

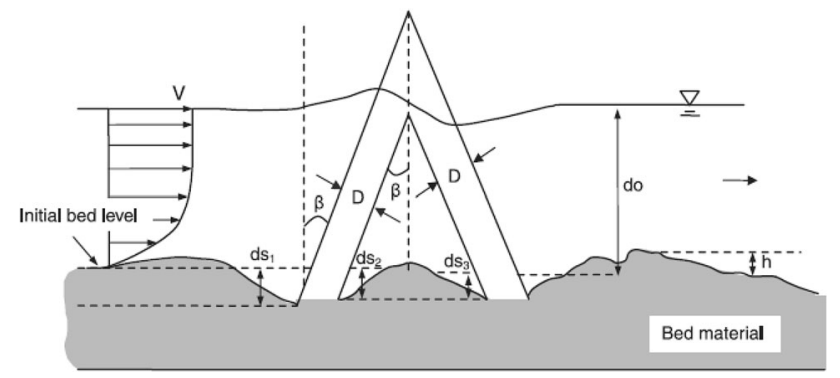

Figure 2. Proposed model by Cesme [15].

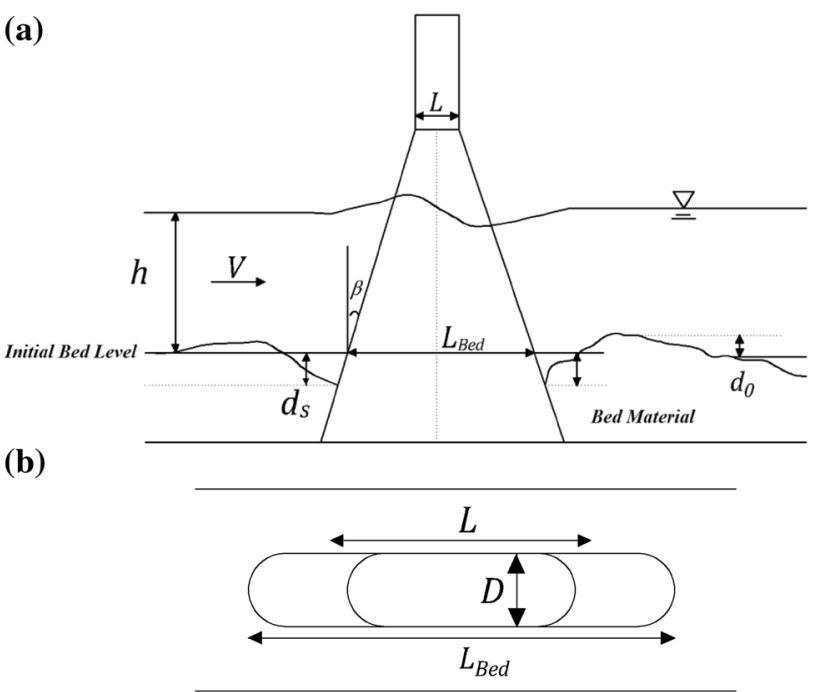

Figure 3. Definition sketch for (a) scour measurements around the sloped pier and (b) cross-section of round-nosed rectangular sloped piers.

\subsection{Dimensionless analysis}

The maximum scour depth, $d_{s}$, around sloped bridge piers are shown with a functional relationship of between different variable as Eq. (1):

$$
d_{s}=f_{1}\left(\rho, \mu, g, V, V_{c}, D, d_{50}, h, L_{B e d}, \beta\right)
$$

where $\rho$ and $\mu$ are water density and viscosity respectively, $g$ is gravitational acceleration, $V$ is depth averaged velocity, $V_{\mathrm{c}}$ is critical depth averaged velocity, $D$ is pier width (or diameter), $d_{50}$ is mean size of sediment particles, $h$ is approaching flow depth, $L_{\text {bed }}$ is pier length at the bed level. $L$ is pier length at the upper section of the pier, and $\beta$ is angle of sloped pier in relation with vertical plane. With selecting $\rho, V$, and $D$ as repeating variables, the non-dimensional relationship achieved based on dimensionless analysis as shown in Eq. (2):

$$
\frac{d_{s}}{D}=f_{2}\left(\frac{\rho V D}{\mu}, \frac{V^{2}}{g D}, \frac{V}{V_{c}}, \frac{D}{d_{50}}, \frac{h}{D}, \frac{L_{B e d}}{D}, \beta\right)
$$

In the second parameter within the parentheses, if $D$ is replaced by flow depth $h$, the Froude number would be appeared in Eq. (2). Ettema et al [17] showed that if the flow around the bridge pier reaches the fully turbulent condition, the pier Reynolds number, $\operatorname{Re}_{D}=\rho V D / \mu$,will not be a significant parameter and can be dropped from the Eq. (2). Then, Eq. (2) rearranged as the form of:

$$
\frac{d_{s}}{D}=f_{2}\left(\frac{V^{2}}{g D}, \frac{V}{V_{c}}, \frac{D}{d_{50}}, \frac{h}{D}, \frac{L_{B e d}}{D}, \beta\right)
$$


Equation (3) indicates that the dimensionless scouring depth of sloped pier, $d_{s} / D$, is a function of the parameters $V^{2} / g D$ flow intensity $V / V_{c}$, relative roughness parameter $D / d_{50}$, normalized approaching flow depth $h / D$, normalized pier length at the bed level $L_{B e d} / D$, and the angle of the sloped pier $\beta$. In addition, it should be noted that to avoid using zero degree angle in regression analyses, the angle of $\alpha$ is utilized instead of $\beta$ and defined as $\alpha^{\circ}=90-\beta^{\circ}$. While performing of experiments, these dimensionless parameters are considered.

\section{Experimental study}

\subsection{Experimental set-up}

All experiments were conducted in a flume of $1 \mathrm{~m}$ wide, $12 \mathrm{~m}$ long and $0.85 \mathrm{~m}$ deep (figure 4). The flume is equipped with a pump of $80 \mathrm{~L} / \mathrm{s}$ capacity. The water temperature in the flume was around 15 to 20 degrees centigrade. The center of pier models placed at $6 \mathrm{~m}$ downstream of the flume entrance. The flow was controlled at the flume outlet by means of a tail gate. In order to carry out sensitivity analysis, the measured stream-wise velocity with a laser current meter was compared with the log law of this hydrodynamic parameter (see figure 5). A 2D laser scanner profiler with $\pm 0.4 \mathrm{~mm}$ accuracy was utilized to digitize the eroded surface at the end of the tests.

Figure 4a shows a sand pit of $2 \mathrm{~m}$ long, $1 \mathrm{~m}$ wide and $0.20 \mathrm{~m}$ deep that prepared in the test section. Only one type

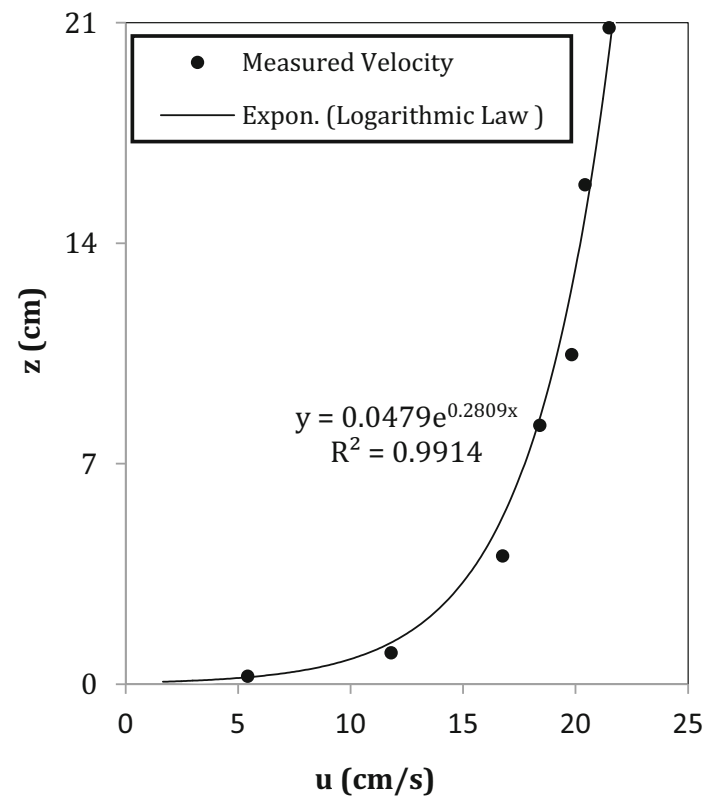

Figure 5. Velocity profile in the vertical direction $(V=22 \mathrm{~cm} / \mathrm{s})$.

of sand as the bed material was used with $d_{50}=0.72 \mathrm{~mm}$, $\gamma_{s}=26.5 \mathrm{kN} / \mathrm{m}^{3}, \phi_{s}=35^{\circ}$, and $\sigma_{g}=1.2$. For the model piers, two different widths of $40 \mathrm{~mm}$ and $60 \mathrm{~mm}$ were selected. The length to width ratio of piers determined to be 3 in all models, so in piers with $40 \mathrm{~mm}$ width, the pier length is $12 \mathrm{~cm}$ and in other ones equals $18 \mathrm{~cm}$. Measurements with various flow depths (e.g., $h=10,12,15,18$, and

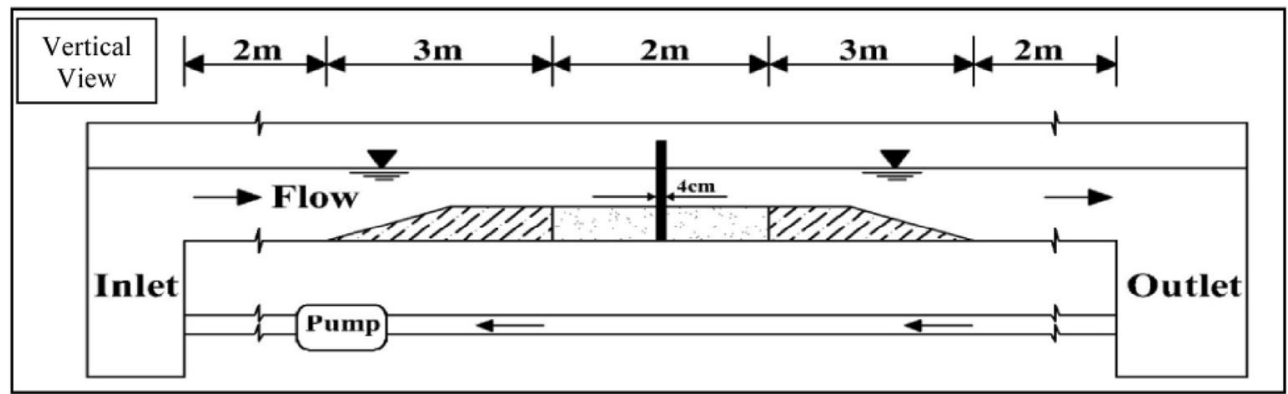

(a)

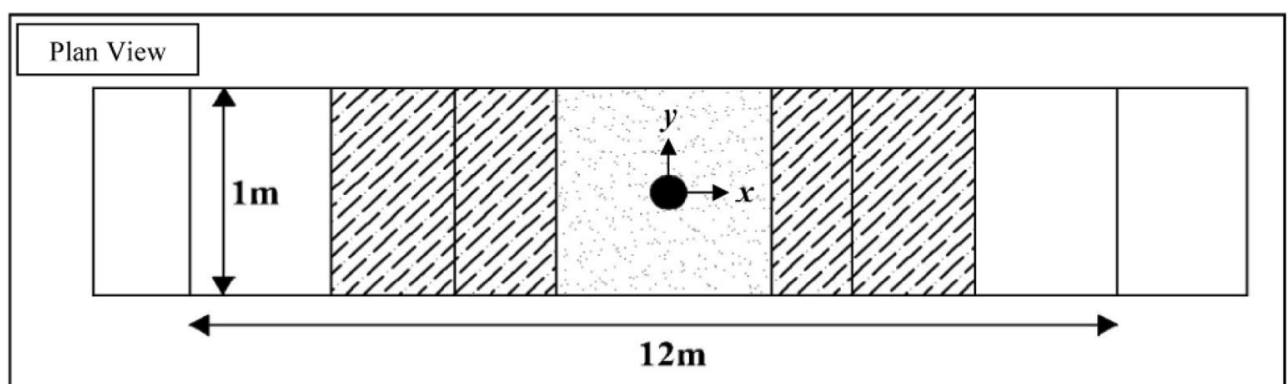

(b)

Figure 4. Water flume (a) vertical view, (b) plan view. 
$21 \mathrm{~cm}$ ), velocities, and corresponding discharges were taken. The experiments were performed for the sloped piers with inclination angles of $0^{\circ}, 5^{\circ}, 10^{\circ}, 20^{\circ}$, and $30^{\circ}$. Experiments were conducted at the steady, clear-water state. Table 1 summarizes the characteristics of the experiments.

During the experiments, erosion of the sediments was measured at the upstream face of the model piers, $d_{\mathrm{s}}$, at a certain time intervals. In addition, the aggradation downstream of the pier, $d_{\circ}$, was measured. In figure 3 , the recording locations of $d_{\mathrm{s}}$ and $d_{\circ}$ are shown. The value of the scouring at downstream face of the pier has not been presented here because it has a relatively small value in comparison with $d_{\mathrm{s}}$ value. Running time is an important parameter in scouring around the piers. Kumar et al [18] stated the equilibrium of scouring established when no more than $1 \mathrm{~mm}$ of increasing bed erosion happens within a timeframe of $3 \mathrm{~h}$. Based on this definition, in this research, the experiment's termination time, $t_{\max }$, taken as $720 \mathrm{~min}$ $(12 \mathrm{~h})$, which determined is sufficiently long enough to reach the equilibrium state. It should be noted that finding the ultimate equilibrium scouring depths is not the scope of this study and the investigation of the pier slope effect on reduction of scouring depth is the main motivation.

\subsection{Using undisturbed flows to verify the experimental results}

Figure 5 shows measured velocity profile in the depth near the location that the model piers would be installed. The measured depth averaged velocity profiles compared with the logarithmic law (Eq. 4) of the velocity profile:

$$
u(z)=\frac{u_{f}}{\kappa} \ln \left(30 \frac{z}{k_{s}}\right)
$$

where $z$ is the vertical distance from the bed level, $u_{f}$ is the friction velocity, $k_{s}$ is Nikurase Roughness and $\kappa(=0.41)$ is von Kármán constant. This velocity profile is presented for the depth averaged velocity of $V=22 \mathrm{~cm} / \mathrm{s}$.

\subsection{Verification of the experimental results}

The results of the test for base model (cylinder with circular cross section) was verified with the numerical data. To do this, the equation of Melville and Chiew (1999) was used to estimate the time development of scouring around the cylinder circular pier under the steady and uniform flow conditions. The temporal development of the scour depth is calculated by an exponential function (Melville and Chiew [19]), expressed as:

$$
\frac{d_{s}}{d_{s e}}=\exp \left[-0.03\left|\frac{V_{c}}{V} \ln \left(\frac{t}{t_{e}}\right)\right|^{1.6}\right]
$$

where $d_{s e}$ is the equilibrium scour depth, and $t_{e}$ is the time that the scour depth approached to the equilibrium state. The equilibrium scour depth are estimated as follows:

$$
d_{s e}=k_{y D} k_{i} k_{d}
$$

where $d_{s e}$ is the equilibrium scour depth, $k_{y D}$ is the flow depth and pier diameter coefficient, $k_{i}$ is the coefficient of flow intensity, and $k_{d}$ is the particle size coefficient. Figure 6 shows the time development of the relative scour depth $\left(d_{s} / d_{s e}\right)$ for the experimental results and the numerical data achieved from Eq. (5).

\section{Experimental results}

The time development of scouring depth at upstream face of the pier $\left(d_{s}\right)$ for $\mathrm{D}=40 \mathrm{~mm}, \mathrm{~h} / \mathrm{D}-3.75$ and different slopes is shown in figure 7 . The rate of mean bed level variation (averaged over $3 \mathrm{~h}$ ) at the upstream face of the model piers is less than $1 \mathrm{~mm}$; i.e., about $0.005 \mathrm{D}$ per hour. The scouring depth for all tests reaches equilibrium state approximately passing about $7 \mathrm{~h}$ from the beginning of the test and then the scouring remains almost constant with no considerable changes during the test running.

\subsection{Experiments with sloped piers}

Table 2 lists the experimental data obtained from five different discharge values for the model piers of $40 \mathrm{~mm}$, and $60 \mathrm{~mm}$ width $\left(\beta=0^{\circ}\right)$. In all cases, the maximum scouring depth observed at upstream edge of the pier. In addition, aggradation of the scoured sediments, showed with $d_{\circ}$, observed at the pier downstream.

Data in table 2 shows that the scouring depth increases with increasing the discharge value, which lead to increase the sediment aggradation at the downstream of the pier. In addition, as the pier is widened, the maximum scouring depth and the amount of aggradation downstream of the pier increase remarkably. Moreover, with increasing the pier width, not only the scouring depth increases, but also

\begin{tabular}{|c|c|c|c|c|c|c|c|}
\hline Parameter & Flow rate $(\mathrm{L} / \mathrm{s})$ & Depth averaged velocity $(\mathrm{m} / \mathrm{s})$ & $\mathrm{V} / \mathrm{Vc}$ & $d_{50}(\mathrm{~mm})$ & Critical shields number & $\begin{array}{l}\text { Duration } \\
\text { (h) }\end{array}$ & $\begin{array}{l}\text { Froude } \\
\text { number }\end{array}$ \\
\hline Value & 65 & 0.225 & 0.92 & 0.72 & 0.031 & 35 and 48 & 0.232 \\
\hline
\end{tabular}
the scoured area expands in all directions and a large zone

Table 1. Summarized characteristics of the tests. 


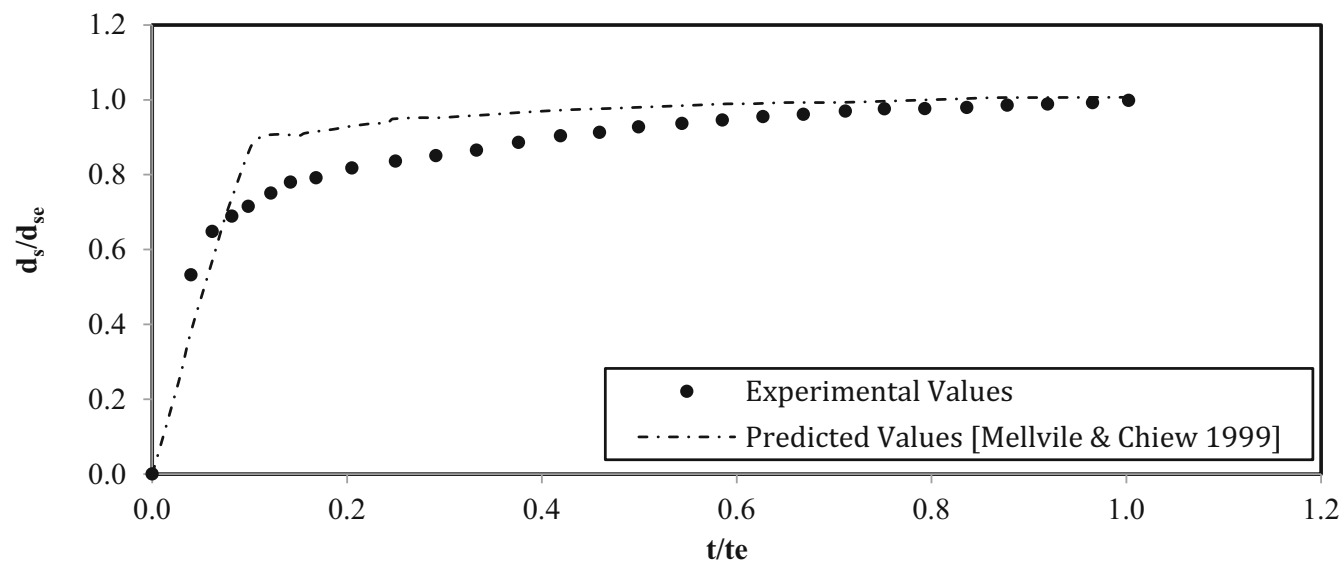

Figure 6. Time development of the maximum scour depth resulted from the experimental test and numerical data (Melville and Chiew 1999) for cylindrical circular pier.

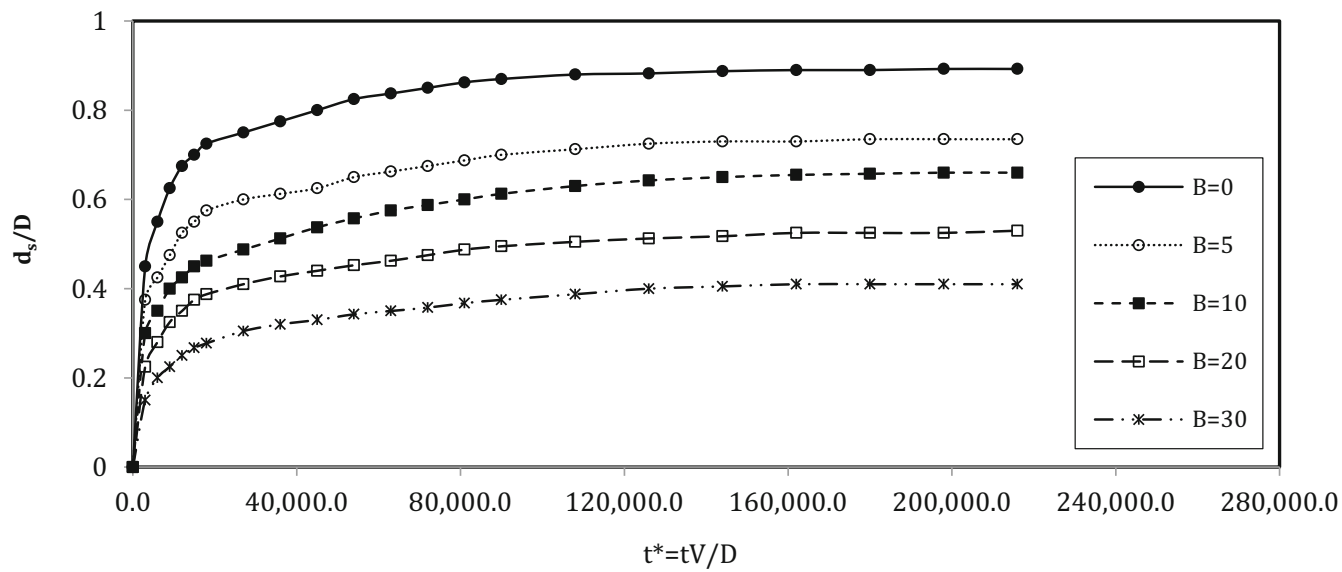

Figure 7. Time history of scouring depth at upstream face of the piers $(\mathrm{D}=40 \mathrm{~mm}, \mathrm{~h} / \mathrm{D}=3.75)$.

Table 2. Experimental data for the pier with $\beta=0^{\circ}\left(\right.$ or $\left.\alpha=90^{\circ}\right)$.

\begin{tabular}{lccccc}
\hline No. & $D(\mathrm{~mm})$ & $L_{\text {Bed }}(\mathrm{cm})$ & $Q(\mathrm{~L} / \mathrm{s})$ & $d_{s} / D$ & $d_{0}(\mathrm{~mm})$ \\
\hline 1 & 40.00 & 12.00 & 15.00 & 0.81 & 4.80 \\
2 & 40.00 & 12.00 & 21.60 & 0.84 & 5.50 \\
3 & 40.00 & 12.00 & 30.00 & 0.89 & 5.90 \\
4 & 4.00 & 12.00 & 39.60 & 0.97 & 6.70 \\
5 & 40.00 & 12.00 & 46.20 & 1.09 & 7.50 \\
6 & 60.00 & 18.00 & 15.00 & 0.69 & 9.80 \\
7 & 60.00 & 18.00 & 30.00 & 0.73 & 10.60 \\
8 & 60.00 & 18.00 & 39.60 & 0.87 & 11.70 \\
\hline
\end{tabular}

of scoured area creates around the pier. Table 3 indicates the obtained experimental results for the piers with inclination angle of $\beta=5^{\circ}$, and width of 40 and $60 \mathrm{~mm}$. As obvious from data in table, the scouring depth for this pier group is smaller than those observed for the vertical piers $\left(\beta=0^{\circ}\right)$. The averaged value of scouring depth reduction is about $18 \%$ relative to the vertical one. Despite the pier inclination angle, aggradation of sediments also occurred at 
the downstream of the piers. In these models, by increasing the discharge value, the scouring depth increases considerably, but the rate of increase is much more than that in the vertical models.

Similar data for the piers with $\beta$ of $10^{\circ}$ and $20^{\circ}$ indicate that the maximum scouring depth decreases as the pier angle, $\beta$, increases (tables 4 and 5). The values of maximum $d_{s}$ in these models are smaller than the associated values in models with $\beta$ of $0^{\circ}$ and $5^{\circ}$. In addition, in these models the decrement rate of scouring is considerable as compared with the other ones. The data revealed that the aggradation at downstream face of the piers reduces with decreasing the scour depth. The aggradation occurred when the eroded sediments from the scouring hole at upstream and two sides of the pier accumulated at the pier downstream. Therefore, decreasing the erosion at upstream face led to decrease in aggradation at downstream.

Table 6 presents the results of the tests conducted with the maximum used inclination angle; i.e., $\beta=30^{\circ}$. It is seen that the $d_{s}$ decreases substantially as the pier inclination angle increases even further. As expected, these model piers have smaller values of scouring depth among the sloped piers and also the values of aggradation are considerably less than that of other models. It can be concluded that with an increase in the inclination angle of piers, not only the upstream slope of the pier weaken the downward jet and prevent it directly hitting to the bed, but also the

Table 4. Experimental data for the pier with $\beta=10^{\circ}\left(\right.$ or $\left.\alpha=80^{\circ}\right)$.

\begin{tabular}{lccccc}
\hline No. & $D(\mathrm{~mm})$ & $L_{\text {Bed }}(\mathrm{cm})$ & $Q(\mathrm{~L} / \mathrm{s})$ & $d_{s} / D$ & $d_{0}(\mathrm{~mm})$ \\
\hline 17 & 40.00 & 26.00 & 15.00 & 0.48 & 3.50 \\
18 & 40.00 & 26.00 & 21.60 & 0.49 & 4.00 \\
19 & 40.00 & 26.00 & 30.00 & 0.53 & 4.70 \\
20 & 4.00 & 26.00 & 39.60 & 0.61 & 5.10 \\
21 & 40.00 & 26.00 & 46.20 & 0.72 & 5.60 \\
22 & 60.00 & 32.00 & 15.00 & 0.43 & 6.90 \\
23 & 60.00 & 32.00 & 30.00 & 0.49 & 7.80 \\
24 & 60.00 & 32.00 & 39.60 & 0.56 & 8.90 \\
\hline
\end{tabular}

Table 5. Experimental data for the pier with $\beta=20^{\circ}\left(\right.$ or $\left.\alpha=70^{\circ}\right)$.

\begin{tabular}{lccccc}
\hline No. & $D(\mathrm{~mm})$ & $L_{\text {Bed }}(\mathrm{cm})$ & $Q(\mathrm{~L} / \mathrm{s})$ & $d_{s} / D$ & $d_{O}(\mathrm{~mm})$ \\
\hline 25 & 40.00 & 41.00 & 15.00 & 0.48 & 4.00 \\
26 & 40.00 & 41.00 & 21.60 & 0.49 & 4.40 \\
27 & 40.00 & 41.00 & 30.00 & 0.53 & 4.70 \\
28 & 4.00 & 41.00 & 39.60 & 0.61 & 5.00 \\
29 & 40.00 & 41.00 & 46.20 & 0.72 & 5.50 \\
30 & 60.00 & 47.00 & 15.00 & 0.43 & 6.40 \\
31 & 60.00 & 47.00 & 30.00 & 0.49 & 7.30 \\
32 & 60.00 & 47.00 & 39.60 & 0.56 & 8.00 \\
\hline
\end{tabular}

Table 6. Experimental data for the pier with $\beta=20^{\circ}\left(\right.$ or $\left.\alpha=70^{\circ}\right)$.

\begin{tabular}{lccccc}
\hline No & $D(\mathrm{~mm})$ & $L_{\text {Bed }}(\mathrm{cm})$ & $Q(\mathrm{~L} / \mathrm{s})$ & $d_{s} / D$ & $d_{0}(\mathrm{~mm})$ \\
\hline 33 & 40.00 & 58.00 & 15.00 & 0.34 & 3.70 \\
34 & 40.00 & 58.00 & 21.60 & 0.38 & 3.90 \\
35 & 40.00 & 58.00 & 30.00 & 0.41 & 4.20 \\
36 & 4.00 & 58.00 & 39.60 & 0.44 & 4.50 \\
37 & 40.00 & 58.00 & 46.20 & 0.50 & 4.90 \\
38 & 60.00 & 64.00 & 15.00 & 0.32 & 5.90 \\
39 & 60.00 & 64.00 & 30.00 & 0.34 & 6.70 \\
40 & 60.00 & 64.00 & 39.60 & 0.40 & 7.40 \\
\hline
\end{tabular}

cross-section and the increased length of the pier help to decrease the scouring.

The development of the local scouring mainly caused with streamline contraction at the two sides of the pier, and the horseshoe vortex in front of the pier. Cross-section of the pier can considerably affect the flow pattern and the role of these parameters. Streamlining the front of the pier can reduce the strength of the horseshoe vortexes, and streamlining the downstream end can reduce the strength of the wake vortexes [20]. Previous studies confirmed that in circular piers, the scouring firstly is observed at two sides of the pier at $\theta= \pm 45^{\circ}$ relative to the flow direction, and the flow separation is the only reason of scouring initiation and development. Then, the scouring is extended from the $\theta= \pm 45^{\circ}$ to the $\theta=0^{\circ}$ (channel axis) and the vertical down-flow intensified the bed erosion at this point. In rectangular shaped piers, the flow separation is initiated from the sides of the pier at about $\theta= \pm 55^{\circ}$ and the scouring is extended to the upstream with considerable delay relative to the circular ones. In addition, it is not observed any extension to the downstream because of the pier length. The high length of the pier in all models causes the eroded sediments accumulated at two sides of the pier and do not transferred to the downstream. In addition, the considerable decrease in aggradation is due to the streamlined form of the model at the downstream, which lead to decrease the effect of wake vortexes behind the pier.

\subsection{Effect of dimensionless parameters on the scouring depth}

3.2a Effect of flow intensity: The effect of different dimensionless parameters, which obtained in the dimensional analysis, on normalized scour depth is important. To investigate these effects, figures $8,9,10$ and 11 are constructed based on these parameters. Figure 8 shows the variation of normalized scouring depth with the flow intensity. Five different flow intensities ranging between 0.476 and 0.685 were tested along all configurations. Results showed that the bed scouring intensifies as flow intensity rises and they depend together linearly. It is 


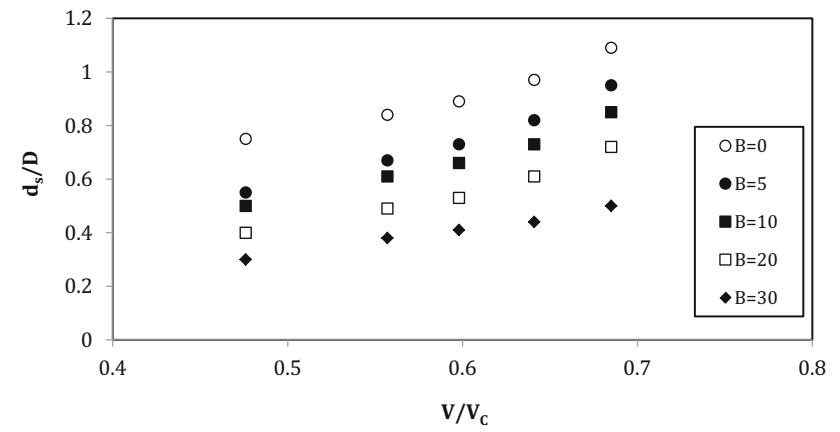

Figure 8. Variation of normalized scour depth respect to the flow intensity $(D=40 \mathrm{~mm}, L=12 \mathrm{~cm})$.

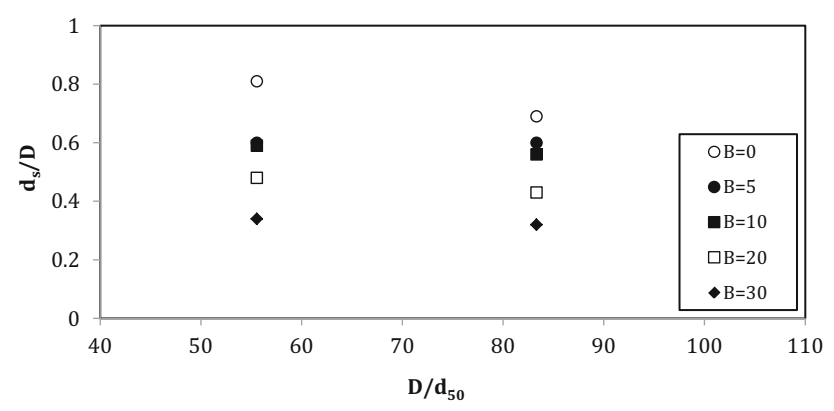

Figure 9. Variation of normalized scour depth respect to the pier size $(V=0.15 \mathrm{~m} / \mathrm{s}, L=12 \mathrm{~cm})$.

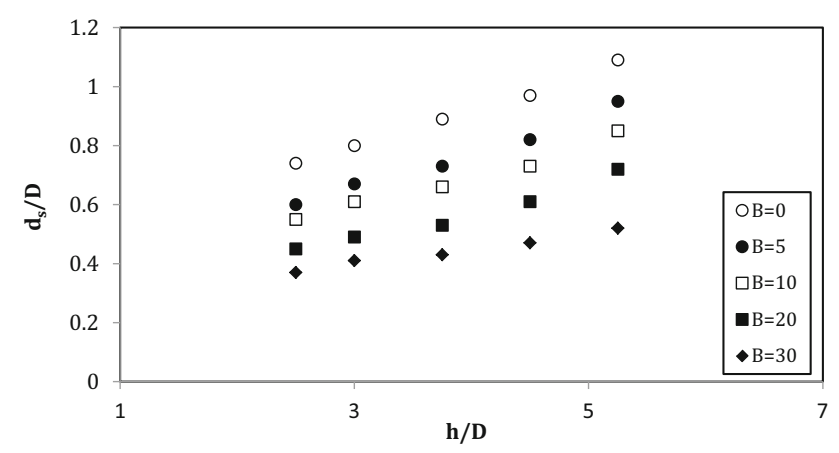

Figure 10. Variation of normalized scour depth respect to the relative flow depth $(D=40 \mathrm{~mm}, L=12 \mathrm{~cm})$.

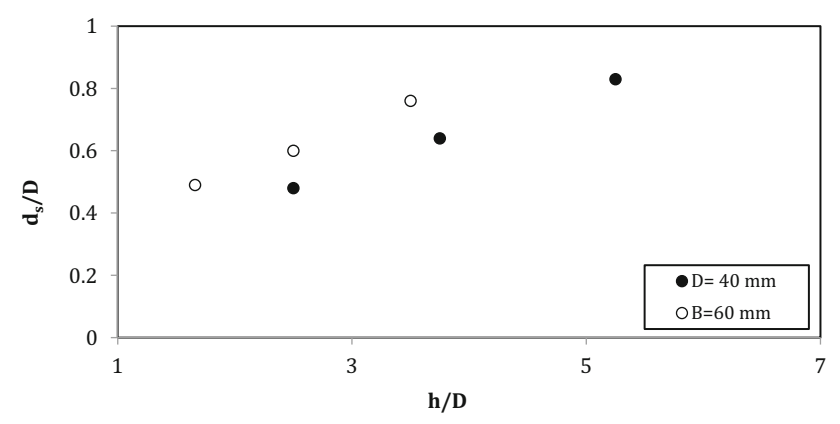

Figure 11. Variation of normalized scour depth respect to the relative flow depth but constant pier diameter $(L=12 \mathrm{~cm})$. obvious that at high flow intensities, the scouring at upstream region take places faster and greater relative to the low values of flow intensities. In addition, the value of the inclination angle affects $d_{s} / D$ simultaneously with the flow intensity. When the inclination angle increases, the effect of flow intensity on scouring is decreased. In pier having $\beta=5^{\circ}$, the difference between the $d_{s} / D$ in high and low values of flow intensities is about $45 \%$, however, in pier with $\beta=30^{\circ}$, this difference reaches to almost $30 \%$.

3.2b Effect of pier size: Figure 9 presents the variation of normalized scouring depth versus the pier size. In this study, two pier diameters of $40 \mathrm{~mm}$ and $60 \mathrm{~mm}$ are used along the tests. The effect of pier size on scouring depth is not considerable and only about $15-20 \%$ increase in maximum scour depth was observed when the pier diameter increases from 40 to $60 \mathrm{~mm}$. In addition, deposition of sediments at the downstream section of the pier increased by increasing the pier diameter.

3.2c Effect of flow depth: The effect of flow depth that ranges from 100 to $210 \mathrm{~mm}$ are tested also in this study. Since in the present study, two size of pier are examined, firstly the variation of scour depth with the flow depth is investigated by $40 \mathrm{~mm}$ diameter pier and then the effect of pier size and relative scour depth have been studied. Figure 10 shows the variation of normalized scour depth regarding to the relative flow depth. As seen in this figure, when the flow depth increases (increasing the relative flow depth) and the pier diameter is constant, the scouring depth and the scouring hole size also increase. In addition, the simultaneously effect of pier inclination angle and the flow depth on scouring is obvious. In pier having $\beta=0^{\circ}$, by increasing the relative flow depth from 2.5 to 5.25 , the normalized scour depth increases about $32 \%$, however, in pier with inclination angle of $\beta=30^{\circ}$, the $d_{s} / D$ increases almost $24 \%$ with increasing the $50 \%$ of the relative scour depth. It is concluded that the inclination angle also affect the flow depth effect, in which by increasing the inclination angle, the effect of flow depth is decreased approximately up to $8 \%$.

In figure 11, it is presented the effect of relative flow depth on scouring depth while the pier diameter kept constant. Regarding that only three flow depth are examined in model piers with $60 \mathrm{~mm}$ diameter, the three relative flow depth is also considered. This figure shows that at a constant flow depth, increasing the pier diameter causes to generation of deeper scouring hole. On the other hand, the effect of pier size outweighs the effect of relative flow depth. However, the slope of the $d_{s} / D$ variation line for both pier diameters of $40 \mathrm{~mm}$ and $60 \mathrm{~mm}$ is close to each other. This shows that the effect of $60 \mathrm{~mm}$ diameter pier on scouring depth is similar to the $40 \mathrm{~mm}$ diameter pier.

3.2d Effect of inclination angle: The effect of inclination angle on the scouring depth was investigated by setting its value to $0^{\circ}, 5^{\circ}, 10^{\circ}, 20^{\circ}$ and $30^{\circ}$. Figure 12 shows variation 


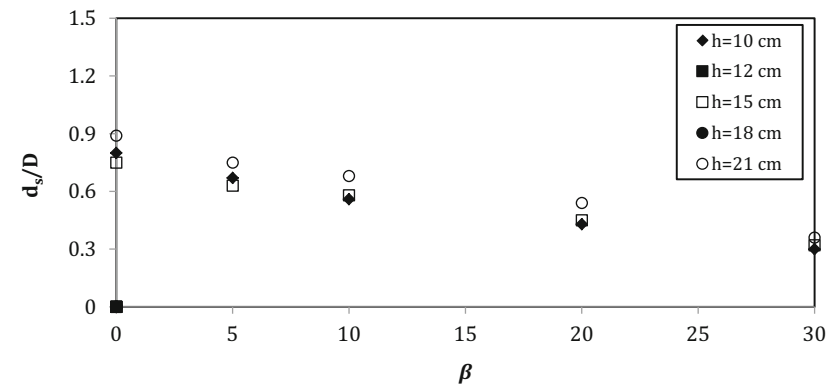

Figure 12. Variation of normalized scour depth respect to the inclination angle $(\mathrm{D}=40 \mathrm{~mm}, L=12 \mathrm{~cm})$.

of normalized scouring depth in terms of inclination angle at different flow depths for pier diameter of $40 \mathrm{~mm}$.

It is clearly seen that the scouring depth decreases significantly as the $\beta$ increases and trend of change at various flow depth is similar. For flow depth of $100 \mathrm{~mm}$, the difference between $d_{s} / D$ values at $\beta$ of $0^{\circ}$ and $30^{\circ}$ is about $60 \%$ and corresponding value for flow depth of $210 \mathrm{~mm}$ diminishes slightly to $55 \%$. In addition, for a constant value of inclination angle, the influence of flow depth was also investigated. At $\beta=0^{\circ}$, when the flow depth rises from 100 to $210 \mathrm{~mm}$ resulted about $25 \%$ increase in $d_{s} / D$ ratio. This increment value is about $32 \%, 36 \%$, and $38 \%$ for $\beta$ of $5^{\circ}$, $10^{\circ}, 20^{\circ}$ and $30^{\circ}$, respectively. It means that the effect of flow depth at different values of inclination angles approximately is constant.

\section{Analysis program}

\subsection{Regression analysis}

One of the most widely used statistical tools that utilized to analyze the multifactor data is Regression Analysis (RA). It is appealing because a conceptually simple method provided to investigate the functional relationships between different variables. It may be broadly utilized to develop relationships among variables, and provide a simple method for establishing a functional relationship between dependent and independent variables, such as $y=f\left(x_{1}, x_{2}, \ldots, x_{k}\right)$. In many problems, however, the selection of dependent variables for the RA model is not predetermined and, often, the first step of the analysis may be the selection of these variables. Some techniques, such as step-wise, forward, and backward selection procedures, can be used for this purpose [21].

After selecting the $k$ terms (among $i$ terms) of variables, which will be included in the equation $y=f\left(x_{1}, x_{2}, \ldots, x_{k}\right)$ and statistical evaluations, the form of function $f$ and its regression coefficient $\left(R^{2}\right)$, are determined. Therefore, at first, it is assumed that in the range of measurements, function $y=f\left(x_{1}, x_{2}, \ldots, x_{k}\right)$ estimates dependent variable based on the independent variables. Then, the assumption is checked by residual analysis. To compare the fitted model in equation $y=f\left(x_{1}, x_{2}, \ldots, x_{k}\right)$ with the measured data set, the most widely used evaluation indices are considered including; Correlation Coefficient $(R)$, Average of Sum of Square Error $(S S E / n)$, Average of Absolute Error $(A A E / n)$ and the distribution of standardized value of residuals $\left(e_{i s}\right)$. In the introduced indices, $n$ shows the number of the data set. The entire constant coefficient estimated by the method of Least Square Errors, which involves minimizing the sum of the square of the residuals set [22].

Table 7. Values of $a_{i}$ parameters in Eq. (7).

\begin{tabular}{lllll}
\hline Test No. & \multicolumn{1}{c}{$\mathrm{Q}$} & \multicolumn{1}{c}{$\mathrm{a}_{0}$} & \multicolumn{1}{c}{$\mathrm{a}_{1}$} & \multicolumn{1}{c}{$\mathrm{a}_{2}$} \\
\hline 1 & 15 & 0.02307 & 1.82500 & 0.38700 \\
2 & 21.6 & 0.02817 & 1.86000 & 0.40150 \\
3 & 30 & 0.02433 & 1.84600 & 0.38950 \\
4 & 39.6 & 0.021481 & 1.8139 & 0.39450 \\
5 & 46.2 & 0.03257 & 1.89700 & 0.41800 \\
\hline
\end{tabular}
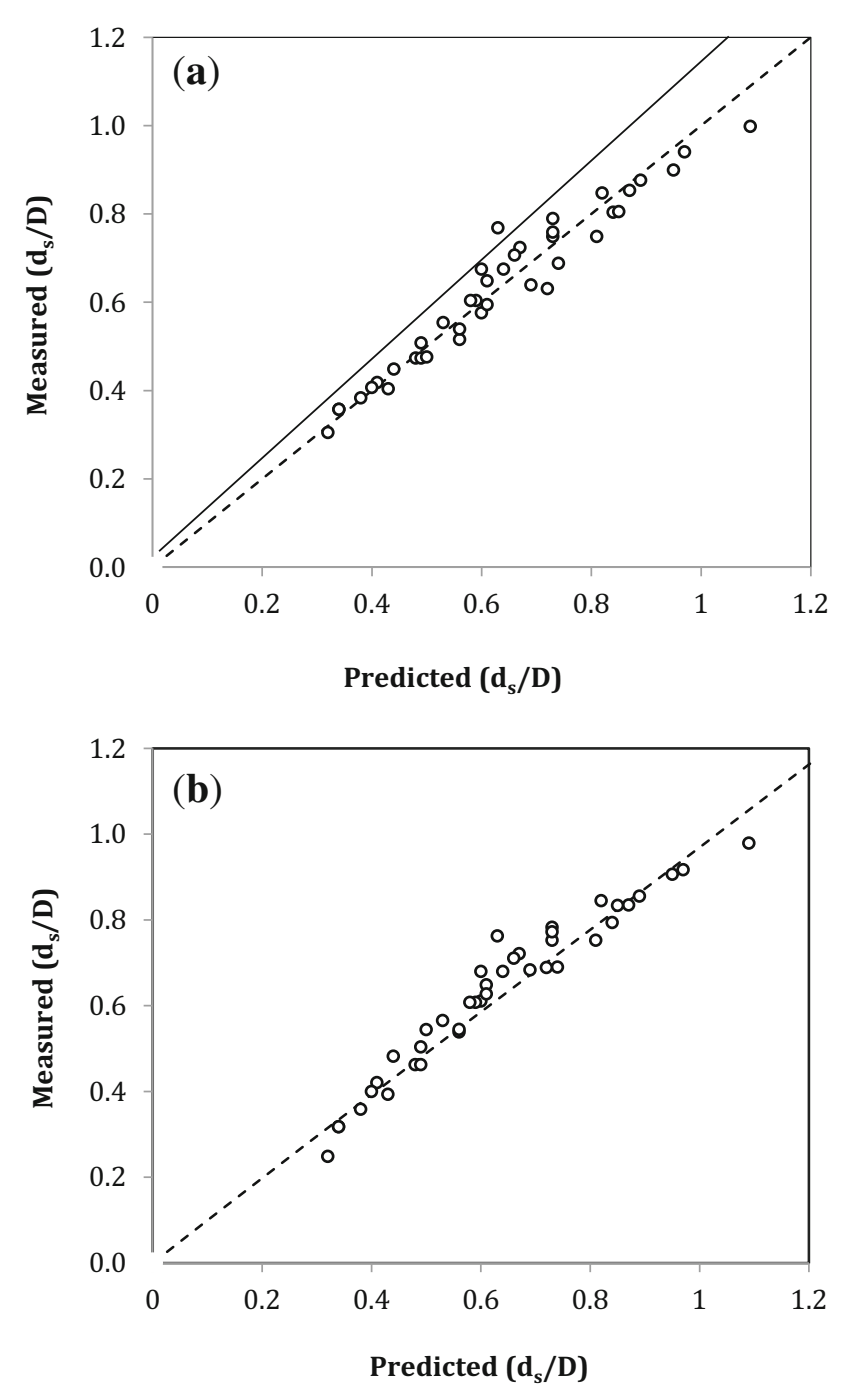

Figure 13. Measured versus predicted values of $d_{s} / D$ : (a) selected and (b) linear, models. 
This methodology was used to present a functional relationship for predicting the value of scouring depth $\left(d_{s}\right)$ at the pier upstream in terms of associated variables. The value of $d_{s} / D$, obtained from the tests, are dependent on the values of the different parameters including $V^{2} / g D$, flow intensity $\left(V / V_{c}\right)$, relative roughness parameter $\left(D / d_{50}\right)$, normalized approach flow depth $(h / D)$, normalized pier length at the bed level $\left(L_{B e d} / D\right)$, and the angle of the sloped pier $(\beta$ or $\alpha(90-\beta))$. Therefore, these parameters selected as independent variables and $d_{s} / D$ was defined as a function of abovementioned non-dimensional variables. Step-wise linear regression showed that the value of $d_{s} / D$ considerably has good correlation only with these two $\alpha$, and $h / D$ dimensionless parameters.

\subsection{Numerical results}

To establish a functional relationship between introduced dependent and independent variables, more than 500 different simple equations in the form of $d_{s} / D=g(\alpha, h / D)$ are investigated by regression tools and ranked by statistical indices. Evaluation of the suggested relationships indicated that the following relationship has the best competence of fitness with the measured data set:

$$
\frac{d_{s}}{D}=a_{0} \alpha^{a_{1}}\left(\frac{h}{D}\right)^{a_{2}}
$$

Therefore, this relationship, with $R^{2}$ value of 0.945 , was selected to determine the scouring depth among proposed models. The values of $a_{i}$ parameters are determined from regression analyses of each test and can be described as
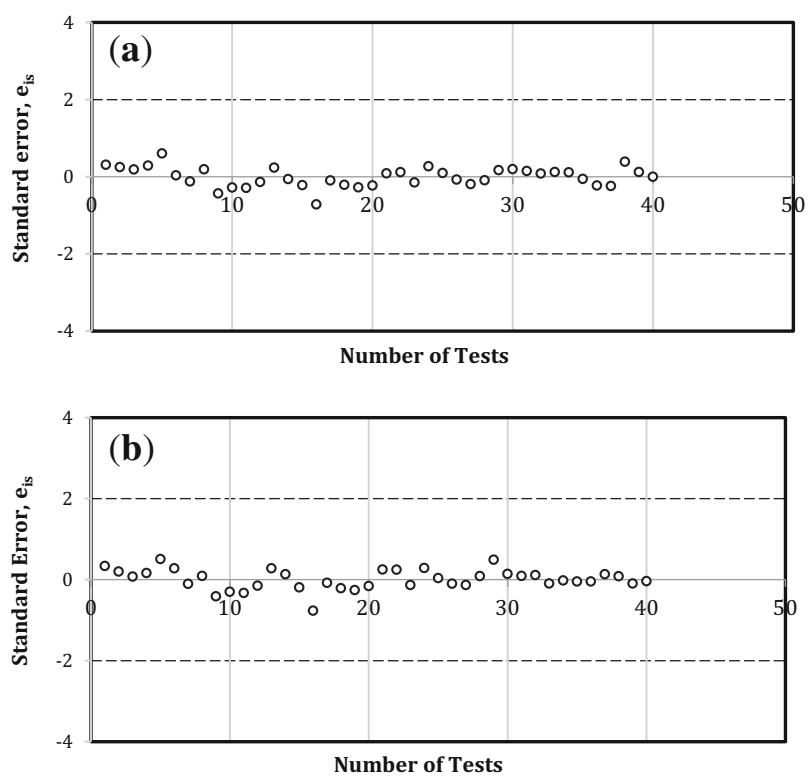

Figure 14. Scatter plots of $d_{S} / D$ (a) suggested and (b) linear, models. presented in table 7. In order to evaluate Eq. (7), a new fitted linear relationship is defined as follows:

$$
\frac{d_{s}}{D}=a_{0}+a_{1} \alpha+a_{2}\left(\frac{h}{D}\right)+\varepsilon
$$

Where $a_{0}, a_{1}, a_{2}$ and $\varepsilon$ are regression parameters of the linear model, with values of $-9.925,0.555,0.28$ and 11.304 , respectively with values of $R^{2}=0.940$.

To evaluate the suitability of Eq. (7), the measured and predicted values of scouring depth, $d_{s} / D$, are compared in figure 13a. It is obvious that almost all data are near the symmetric line and they fall between $\pm 10 \%$ error lines. A similar graph for the linear model has been prepared and
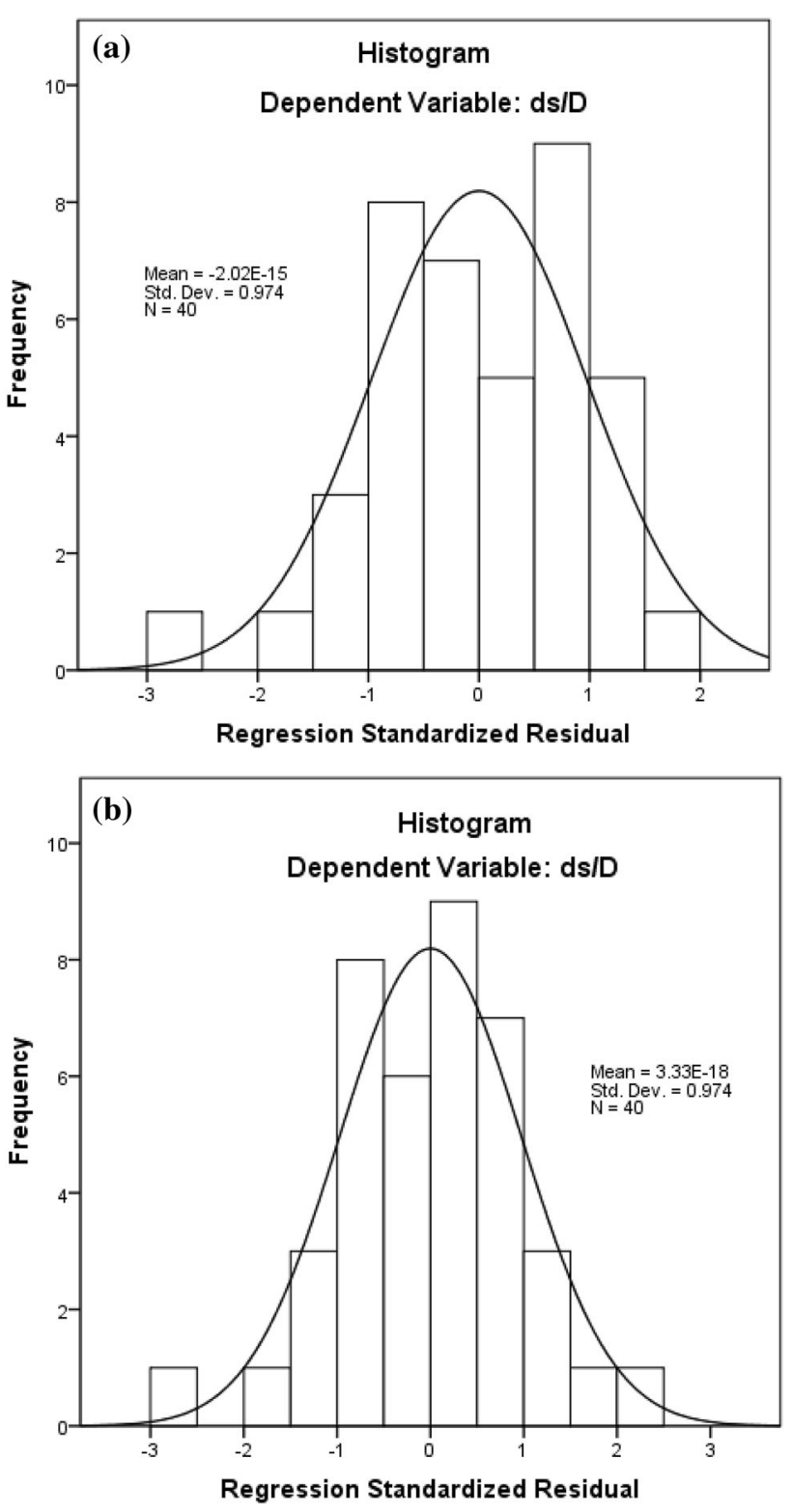

Figure 15. Normal distribution of $e_{i}$ : (a) suggested, (b) linear; models. 
illustrated in figure $13 \mathrm{~b}$. Less scattering of data around the $\mathrm{y}=\mathrm{x}$ line in figure 13a and data presented in table 7 clearly reveal that Eq. (7) can predict scouring depth $\left(d_{s} / D\right)$ better than the linear Eq. (8).

Another index to assess the suitability of the fitted equation is the standardized residual $\left(e_{i s}\right)$, defined as $e_{i s}=\left(y_{i}-\hat{y}_{i}\right) / S . D$. For the most suitable equations, values of the standard deviation and mean of this index must be almost equal to unity and zero, respectively. In addition, if enough number of data set is available, an approximately independent normal distribution is expected for the value of $e_{i s}$ [22].

For the suggested and linear models, the scatter plot of residuals presented in figure 14. This figure shows that the values of $e_{i s}$ fall almost between $(-1,+1)$ and randomly distribute around zero. In addition, it is concluded from this figure that there is no distinct pattern at the distribution of $e_{i s}$, and they do not change in a systematic way with predicted $d_{s} / D$ values. As a rule, the model is acceptable when the values of $e_{i s}$ fall between $(-2,+2)$ and are randomly distributed around zero, and residual plots do not have a distinct pattern of variation. A new introduced parameter, $e_{i}$, defined as the difference between measured and predicted values of a dependent variable. Figure 15 displays the normal distribution of this parameter value. As indicated, an independently random quantity, with a constant variance and a mean value of about zero obtained for the value of $e_{i}$ parameter.

\section{Validation of suggested models}

To evaluate the precision of the models, the experimental and numerical values of $d_{s} / D$ were compared for two pier with width of 40 and $60 \mathrm{~mm}$. Figure 16 shows the variations of scouring depth versus the relative of $h / D$ for this two pier. The graphs show that the suggested model in Eq. (7) can reasonably predict the value of scouring depth. Comparison of average error among the experimental and predicted values indicates that the maximum error in the prediction of $d_{s} / D$ is $21.4 \%$. This means that the suggested model has acceptable accuracy to predict the scouring depth. This evaluation also indicates that the predicted values of $d_{s} / D$ are closer to experimental ones at higher values of $h / D$. In addition, the model can well predict the experimental values for the both large and small values of pier width.

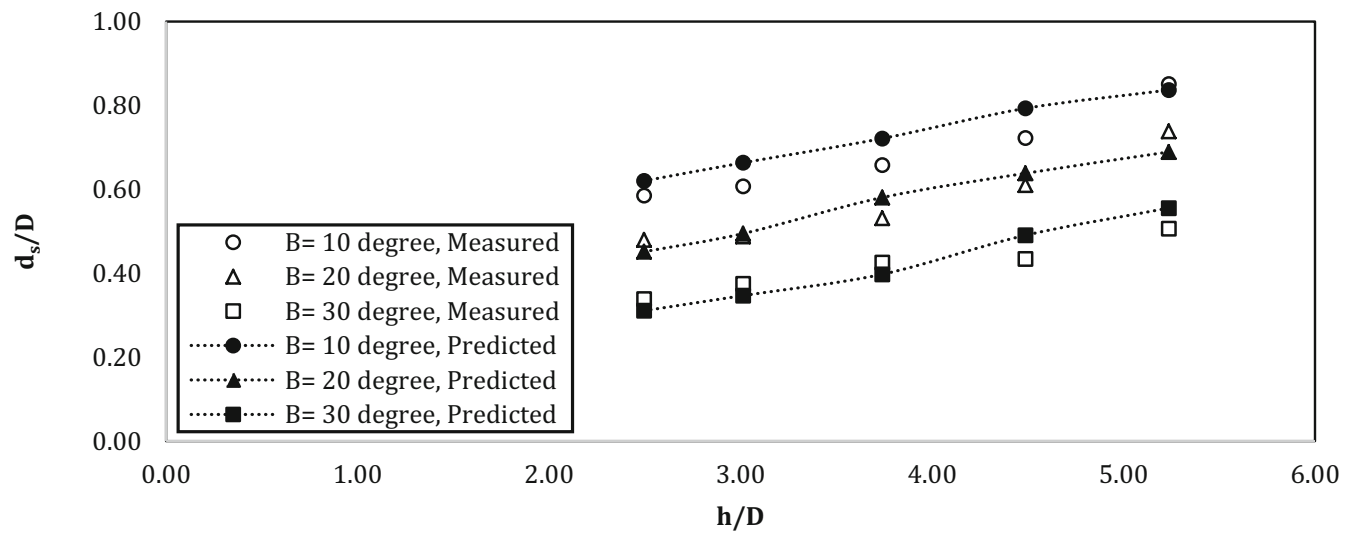

(a)

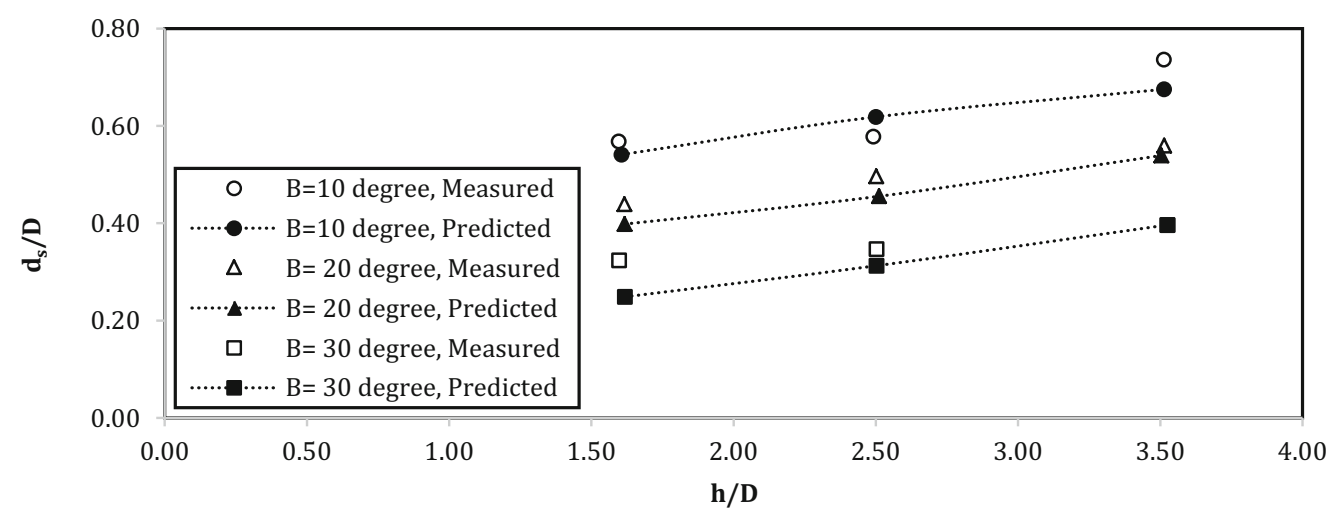

(b)

Figure 16. Variation of measured and predicted values of $d_{s} / D$ versus $h / D$; (a) pier width of $40 \mathrm{~mm}$, (b) pier width of $60 \mathrm{~mm}$. 


\section{Conclusion}

The aim of this study was to determine the effect of the new-sloped model piers with round-nosed rectangular cross-sections on development of local scouring, that the maximum scouring was measured at upstream side of the pier. To do this, a number of 40 experimental tests performed under near water threshold conditions, with uniform bed material with a single bridge pier. The testes continued up to $6 \mathrm{~h}$. The physical tests were conducted for two different pier widths with a range of flow depths, velocities, and corresponding discharges. In addition, the effect of different inclination angles, flow intensities, flow depths, and pier size were investigated. The inclination angle is the most important parameter that was considered in this research.

To determine the local scouring around piers, conduction of experimental testing is both time consuming and costly. Therefore, it is useful and sometimes inevitable to use statistical based regression equations to estimate its value. Two reliable correlations, based on regression analysis, using test data presented here, were proposed here to estimate the local scouring around proposed new-sloped piers. These models use some parameters, such as flow intensity, relative roughness parameter, normalized approaching flow depth, normalized pier length at the bed level, and the inclination angle of the sloped pier, which are relatively simple to use, although they need some constant parameters. The main conclusions of the experimental section of this study are summarized as follows:

- The scouring depth increases with increasing the discharge value and this lead to increase in the sediment aggradation at the downstream of the pier.

- Five different flow intensities ranging between 0.476 and 0.685 were tested. Increasing the flow intensity increases the normalized scour depth linearly. It is obvious that at higher flow intensities, the scouring at upstream region take place faster and greater relative to the lower values of flow intensities. In addition, the inclination angle affects the normalized scour depth simultaneously with the flow intensity. With increasing the inclination angle, the effect of flow intensity on scouring decreases.

- Effect of pier size, 40 and $60 \mathrm{~mm}$, on scour depth was not considerable and only about $15-20 \%$ increases in maximum scour depth is observed when the pier diameter increases from 40 to $60 \mathrm{~mm}$.

- Effect of flow depth ranging between 100 and $210 \mathrm{~mm}$ was also tested. Increasing the flow depth (increasing the relative flow depth) in state of constant pier diameter, cause to increase the scouring depth and the scouring hole size. In addition, simultaneous effect of the pier inclination angle and the flow depth on scouring is obvious. It is ranging from 20 to $40 \%$. Therefore, it is concluded that the inclination angle affect the flow depth effect, in which by increasing the inclination angle, the effect of flow depth is decreased approximately up to $8 \%$. In other state, at a constant flow depth, increasing the pier diameter causes generation of deeper scouring hole. It is obvious that the slope of the line of normalized scour depth variation for both pier diameters of $40 \mathrm{~mm}$ and $60 \mathrm{~mm}$ is close to each other.

- To investigate the effect of pier inclination, five angles of $0^{\circ}, 5^{\circ}, 10^{\circ}, 20^{\circ}$ and $30^{\circ}$ were tested. It was clearly seen that the scouring depth decreases significantly as the inclination angle increases. In addition, the effect of flow depth at different inclination angles is similar to each other. In addition, investigating the effect of flow depth on scouring at a constant value of inclination angle revealed that increasing the flow depth lead to increasing the scouring depth about $25 \%$. This shows that at different values of inclination angles, the effect of flow depth variation is similar.

- Statistical indices and residual analyses of the models show the suitability of the proposed models. In addition, comparison of the experimental and predicted values of normalized scouring depth illustrates that the suggested models can reasonably predict this parameter. A comparison of maximum average error (\%) between experimental and predicted values displayed that the scouring prediction is comparatively accurate.

\section{References}

[1] Breusers H N C, Nicollet G and Shen H W 1977 Local scour around cylindrical piers. J. Hydraul. Re. 15(3): 211-252. https://doi.org/10.1080/00221687709499645

[2] Barbhuiya A K and Dey S 2004 Local scour at abutments: A review. Sadhana 29(5): 449-476. https://doi.org/10.1007/ bf02703255

[3] Amini A and Thamer M A 2016 Local scour prediction around piers with complex geometry. Mar. Georesour. Geotechnol. 35(6): 857-864. https://doi.org/10.1080/ 1064119x.2016.1256923

[4] Diab R M A E A 2011 Experimental investigation on scouring around piers of different shape and alignment in gravel, PhD Thesis, TU Darmstadt, Darmstadt, Deutschland

[5] Melville M W 1975 Local scour at bridge sites. Project Report No. 117, School of Engineering, University of Auckland, Auckland, New Zealand, 227 p

[6] Unger J and Hager W H 2007 Down-flow and horseshoe vortex characteristics of sediment embedded bridge piers. Exp. Fluids 42(1): 1-19. https://doi.org/10.1007/s00348-0060209-7

[7] Gobert C, Link O, Manhart M and Zanke U 2010 Discussion of coherent structures in the flow field around a circular cylinder with scour hole by G Kirkil, S G Constaninescu and R Ettema. J. Hydraul. Eng. 136(1): 74-76. https://doi.org/10. 1061/(asce)hy.1943-7900.0000032 
[8] Gaudio R, Tafarojnoruz A and Bartolo S D 2013 Sensitivity analysis of bridge pier scour depth predictive formulae. $J$. Hydroinformatics 15(3): 939-951. https://doi.org/10.2166/ hydro.2013.036

[9] Torok G T, Baranya S and Ruther N 2017 3D CFD modeling of local scouring, bed armoring and sediment deposition. Water 9(56): 1-23. https://doi.org/10.3390/w9010056.

[10] Bozkus Z and Cesme M 2007 Local scour around inclined piers. In: Proceedings of the 18th Canadian Hydrotechnical Conference, Winnipeg, Manitoba, Canada, August 22-24

[11] Breusers H N C and Raudkivi A J 1991 IAHR Hydraulic Structures Design Manual: Scouring, vol. 2. Rotterdam: A. A. Balkema, 143 pp

[12] Sumer B M, Fredsoe J, Christiansen N and Hensen S B 1994 Bed shear stress and scour around coastal structures, R M Ragan (Ed.). In: Proc. 24th International Coastal Engineering Conference. Kobe, Japan: ASCE, pp. 1595-1609

[13] Fredsoe J and Sumer B M 1997 Scour at the round head of a rubble-mound break water. Coast. Eng. 29:12-23. https:// doi.org/10.1061/9780784400890.116

[14] Bozkus Z and Yildiz O 2004 Effects of inclination of bridge piers on scouring depth. J. Hydraul. Eng. 130(8): 827-832. https://doi.org/10.1061/(asce)0733-9429(2004)130: $8(827)$

[15] Cesme M 2005 Experimental investigation of local scour around inclined dual bridge piers. M.Sc. thesis,
Hydromechanics Laboratory, Civil Engineering Department, Middle East Technical University, Ankara, Turkey

[16] Özlap M C 2013 Experimental investigation of local scour around bridge pier groups. M.Sc. thesis, Hydromechanics Laboratory, Civil Engineering Department, Middle East Technical University, Ankara, Turkey

[17] Ettema R, Melville W B and Barkdoll B 1998 Scale effect in pier-scour experiments. J. Hydraul. Eng. 124(6): 639-642. https://doi.org/10.1061/(asce)0733-429(1998)124:6(639)

[18] Kumar V, Raju K G R and Nandana V 1999 Reduction of local scour around bridge piers using slots and collars. $J$. Hydraul. Eng. ASCE 125(12): 1302-5. https://doi.org/10. 1061/(asce)0733-9429(1999)125:12(1302)

[19] Melville B W and Chiew Y M 1999 Time scale for local scour at bridge piers. J. Hydraul. Eng. ASCE 125(1): 59-65 https://doi.org/10.1061/(ASCE)0733-9429(1999)125:1(59)

[20] Richardson E V and Davis S R 2001 Evaluating scour at bridge, 4th edition. Publ. No. FHWA NHI 01-001, HEC-18, Federal Highway Administration, Washington, DC

[21] Benjamin J R and Cornell C A 1970 Probability, Statistics and Decision for Civil Engineering. New York, USA: McGraw Hill

[22] Soltani-Jigheh H, Soroush A and Rezaei M 2012 Estimating undrained cyclic behavior of compacted mixed clayey soils by statistical tools. Sci. Iran. 19(3):346-354. https://doi.org/ 10.1016/j.scient.2012.04.005 